\title{
Helicobacter pylori Eradication Induced Constant Decrease in Interleukin- 1B Expression over More Than 5 Years in Patients with Gastric Cancer and Dysplasia
}

\author{
Hee Jin Kim ${ }^{1,2}$, Nayoung Kim ${ }^{1,3}$, Ji Hyun Park ${ }^{3}$, Sunkyu Choi ${ }^{4}$, Cheol Min Shin ${ }^{1,3}$, and Ok Jae Lee ${ }^{5}$ \\ ${ }^{1}$ Department of Internal Medicine, Seoul National University Bundang Hospital, Seongnam, ${ }^{2}$ Department of Internal Medicine, Gyeongsang \\ National University College of Medicine and Gyeongsang National University Changwon Hospital, Changwon, ${ }^{3}$ Department of Internal \\ Medicine and Liver Research Institute, Seoul National University, Seoul, ${ }^{4}$ Medical Research Collaborating Center, Seoul National University \\ Bundang Hospital, Seongnam, and ${ }^{5}$ Department of Internal Medicine, Institute of Health Sciences, Gyeongsang National University College of \\ Medicine and Gyeongsang National University Hospital, Jinju, Korea
}

Background/Aims: Helicobacter pylori (Hp) suppresses gastric acid secretion by repressing the expression of the $\mathrm{H}^{+}$, $\mathrm{K}^{+}$-adenosine triphosphatase $\left(\mathrm{H}^{+}, \mathrm{K}^{+}\right.$-ATPase $)$and stimulating interleukin-1 (IL-1 $\beta$; encoded by IL-1B). This study was aimed at evaluating the expression of the $\mathrm{H}^{+}, \mathrm{K}^{+}$-ATPase and IL-1 $\beta$ after Hp eradication. Methods: Two hundred twentyone subjects were categorized as Hp-negative $(n=84)$ or $\mathrm{Hp}$ positive ( $n=137$ ) according to the results of Hp tests (histology, CLO test, culturing, and serology). The mRNA expression levels of IL-1B and ATP4A (the gene encoding the $\alpha$-subunit of $\mathrm{H}^{+}, \mathrm{K}^{+}$-ATPase) were measured in biopsy specimens from the gastric corpus using real-time polymerase chain reaction. Results: The Hp-positive group had significantly higher IL-1B mRNA levels than the whole Hp-negative group and the intestinal metaplasia (IM)-negative subgroup. After $\mathrm{Hp}$ eradication, the difference between the Hp-negative and $\mathrm{Hp}$ eradicated groups disappeared, including in the IM-negative subgroup. The IL-1B mRNA level did not significantly change from the baseline level. Within the gastric cancer (GC)/dysplasia subgroup, the IL-1B mRNA levels at 1, 2, 3-4, and $\geq 5$ years after $\mathrm{Hp}$ eradication were significantly lower than the baseline level. The difference in ATP4A mRNA levels between the Hp-negative and Hp-positive groups was not significant at baseline, and the changes in the ATP4A mRNA levels after $\mathrm{Hp}$ eradication compared to the baseline levels in the whole group and subgroups stratified by the presence of IM and GC/dysplasia were not significant. Conclusions: Infection with $\mathrm{Hp}$ has an effect on the level of IL-1B mRNA in
IM-negative subjects. The continuous reduction in the IL-1B mRNA level in patients with GC/dysplasia after Hp eradication contributes to the prevention of metachronous GC after Hp eradication. (Gut Liver 2020;14:735-745)

Key Words: Helicobacter pylori; Interleukin-1 beta; Gastric acid; $\mathrm{H}(+)-\mathrm{K}(+)$-exchanging ATPase

\section{INTRODUCTION}

Helicobacter pylori (Hp) colonization in gastric mucosa causes acute and chronic inflammation, and bacterial virulence factors and host genetic factors determine the severity and pathological sequelae of inflammation. ${ }^{1} \mathrm{H}^{+}, \mathrm{K}^{+}$-adenosine triphosphatase $\left(\mathrm{H}^{+}\right.$, $\mathrm{K}^{+}$-ATPase) of the parietal cell is the final step of gastric acid secretion and is affected by $\mathrm{Hp}^{2}$ In the acute infection stage, Hp represses the activity of the promoter of the alpha-subunit of $\mathrm{H}^{+}, \mathrm{K}^{+}$-ATPase, ${ }^{3}$ and several cytokines, such as interleukin- $1 \beta$ (IL-1 $\beta$; encoded by $I L-1 B$ ) and tumor necrosis factor- $\alpha$, released during this process also suppress acid secretion. ${ }^{4,5}$ As Hp infection progresses into the chronic state, atrophy in the corpus is accelerated, ${ }^{6}$ gastric acid secretion decreases and results in the loss of parietal cells. ${ }^{7}$

Many studies have consistently shown that the suppression of gastric acid secretion in Hp-positive patients with or without atrophy at least partially recovers at a relatively short period, 1 , 3, and 7 months after Hp eradication. ${ }^{8-12}$ Most of the previous studies on gastric acid secretion in Hp-infected subjects were

Correspondence to: Nayoung $\mathrm{Kim}^{\mathrm{a}}$ and Ok Jae Lee ${ }^{\mathrm{b}}$

${ }^{a}$ Department of Internal Medicine, Seoul National University Bundang Hospital, 82 Gumi-ro 173beon-gil, Bundang-gu, Seongnam 13620, Korea

Tel: +82-31-787-7008, Fax: +82-31-787-4051, E-mail: nakim49@snu.ac.kr

${ }^{\mathrm{b}}$ Department of Internal Medicine, Gyeongsang National University College of Medicine, 15 Jinju-daero 816beon-gil, Jinju 52727, Korea

Tel: +82-55-750-8056, Fax: +82-55-758-9122, E-mail: ojlee@gnu.ac.kr

Received on September 18, 2019. Revised on November 16, 2019. Accepted on November 17, 2019. Published online July 27, 2020.

pISSN 1976-2283 eISSN 2005-1212 https://doi.org/10.5009/gnl19312

@ This is an Open Access article distributed under the terms of the Creative Commons Attribution Non-Commercial License (http://creativecommons.org/licenses/by-nc/4.0) which permits unrestricted non-commercial use, distribution, and reproduction in any medium, provided the original work is properly cited. 
based on evaluations of basal and gastrin-stimulated gastric acid output ${ }^{10,12}$ or intragastric $\mathrm{pH}$ monitoring. ${ }^{11}$ Only two studies measured gastric $\mathrm{H}^{+}, \mathrm{K}^{+}$-ATPase activities directly from biopsy specimens and reported a restoration of $\mathrm{H}^{+}, \mathrm{K}^{+}$-ATPase expression at 1 month $^{9}$ and 12 weeks after eradication. ${ }^{8}$ According to Osawa et al., ${ }^{8}$ the expression of gastric $\mathrm{H}^{+}, \mathrm{K}^{+}$-ATPase mRNA was markedly recovered at 12 weeks after $\mathrm{Hp}$ eradication, without alterations in numbers of parietal cell in patients without gastric cancer (GC), suggesting that the recovery of gastric acid secretion after Hp eradication is attributed to the recovery of parietal cell function.

IL-1 $\beta$ plays an important role in initiating and amplifying the inflammatory response against $\mathrm{Hp}$ infection and is also a powerful inhibitor of gastric acid secretion. ${ }^{13,14}$ The activity of the corpus gastritis and gastric juice $\mathrm{pH}$ correlate with the expression of the $I L-1 B$ mRNA. ${ }^{15}$ In addition, significant decreases in the levels of the IL-1 $\beta$ mRNA and protein at an early period (6 or 12 weeks) after Hp eradication were observed in patients without GC. ${ }^{8,15,16}$

As shown in our previous study, intestinal metaplasia (IM) in the antrum and corpus improved significantly only in the Hp- eradicated group compared with the baseline, and the significant difference in IM between Hp-eradicated and -negative groups disappeared after $\geq 5$ years of follow-up in the antrum and after 3 years of follow-up in the corpus. ${ }^{17}$ Therefore, we hypothesized that the influence of $\mathrm{Hp}$ eradication on the $\mathrm{H}^{+}, \mathrm{K}^{+}$-ATPase and IL-1 $\beta$ levels would be differ according to the presence of an IM.

To our knowledge, no comprehensive study has reported the long-term effects of Hp eradication on IL-1 $\beta$ levels and the alterations in both $\mathrm{H}^{+}, \mathrm{K}^{+}$-ATPase and serum pepsinogen (PG) levels after Hp eradication. Thus, the aim of this study was to evaluate the expression of IL-1 $\beta$ and $\mathrm{H}^{+}, \mathrm{K}^{+}$-ATPase and serum PG I/II ratio before and more than 5 years after Hp eradication.

\section{MATERIALS AND METHODS}

\section{Study subjects}

The study subjects who received esophagogastroduodenoscopy (EGD) at the Seoul National University Bundang Hospital between February 2006 and July 2015 were consecutively enrolled. Subjects with a previous gastrectomy and Hp eradication, and patients who did not undergo Hp tests were excluded.

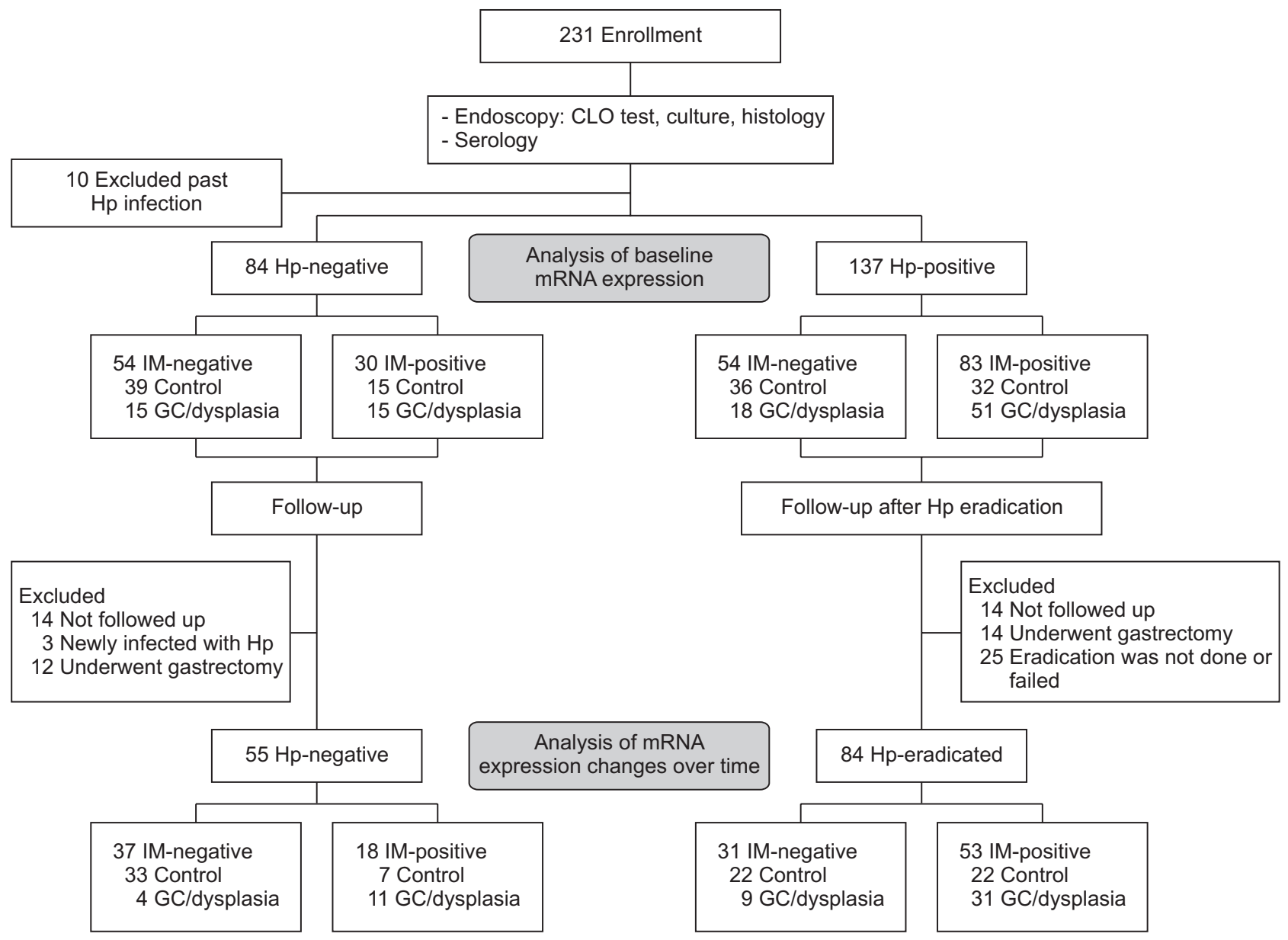

Fig. 1. Proposed study algorithm for the inclusion and classification of subjects. Hp, Helicobacter pylori; IM, intestinal metaplasia; GC, gastric cancer. 
Current Hp-positive subjects received a triple therapy (esomeprazole $40 \mathrm{mg}$ b.i.d. [twice a day], clarithromycin $500 \mathrm{mg}$ b.i.d., and amoxicillin 1,000 mg b.i.d. for 1 week) for Hp eradication. ${ }^{13} \mathrm{C}$ urea breath testing was performed at least 4 weeks after completion of the eradication therapy to evaluate Hp eradication.

Patients with GC/dysplasia underwent complete endoscopic resection at the time of enrollment and were diagnosed with gastric adenocarcinoma or signet ring cell carcinoma, or gastric dysplasia based on the results of final pathologic reports. Patients with GC who treated with gastrectomy were excluded because the microenvironment, such as acid secretion and bile reflux, is potentially altered after gastric resection. ${ }^{18}$ After endoscopic resection, the first EGD was performed within 3 months and then annually thereafter for the patients with $\mathrm{GC} /$ dysplasia. Annual or biannual follow-up endoscopy was recommended for the subjects with benign gastroduodenal diseases, mainly because the Korean recommendation for EGD is a 2-year interval and 1-year interval for subjects at high risk of developing GC.

The study protocol was approved by the Institutional Review Board of Seoul National University Bundang Hospital (IRB number: B-1509/316-302). All subjects provided written informed consent according to ethical principles for medical research of the 53rd World Medical Association Declaration of Helsinki. ${ }^{19}$ This study protocol has been registered at ClinicalTrials.gov (NCT04037904).

\section{Hp testing}

A single doctor (N.K.) performed an EGD and biopsy to maintain consistency in biopsy sites. At each endoscopy, 10 biopsy specimens were obtained for $\mathrm{Hp}$ and histological examinations (Supplementary Fig. 1) during endoscopy. Three Hp tests were performed during the EGD: Giemsa staining, cultures, and CLO test. The presence of a specific immunoglobulin $\mathrm{G}$ for Hp in each subject's serum was screened using an enzyme-linked immunosorbent assay (Genedia $H$. pylori ELISA; Green Cross Medical Science Corp, Eumseong, Korea). The antigen for the Hp antibody test was the Korean strain. If any of three biopsy-based tests reveal a positive result, Hp infection was defined as current. If all three biopsy-based Hp tests and $\mathrm{Hp}$ serology were negative and $\mathrm{Hp}$ was not eradicated prior to the assessment, the subject was defined as Hpnegative. If these three biopsy-based Hp tests were all negative but Hp serology was positive or Hp was eradicated prior to the test, the subject was defined as having a past Hp infection and was excluded from this study.

\section{Serology testing for serum PG levels}

Fasting serum samples obtained from the study subjects were centrifuged immediately at $4^{\circ} \mathrm{C}$ and stored at $70^{\circ} \mathrm{C}$ until use in the experiments. The serum concentrations of PG I and II were measured by a latex-enhanced turbidimetric immunoassay (L-

Table 1. Baseline Characteristics of Study Subjects Stratified According to Helicobacter pylori Status

\begin{tabular}{|c|c|c|c|c|}
\hline Characteristic & $\begin{array}{c}\text { Total } \\
(\mathrm{n}=221)\end{array}$ & $\begin{array}{l}\text { H. pylori-negative } \\
(\mathrm{n}=84)\end{array}$ & $\begin{array}{l}\text { H. pylori-positive } \\
(\mathrm{n}=137)\end{array}$ & $\mathrm{p}$-value \\
\hline Male sex & $107(48.4)$ & $36(42.9)$ & $71(51.8)$ & 0.195 \\
\hline Age, yr & $55.2 \pm 12.0$ & $55.8 \pm 13.6$ & $54.9 \pm 11.3$ & 0.605 \\
\hline BMI, kg/m² & $24.52 \pm 14.54$ & $26.34 \pm 23.24$ & $23.43 \pm 3.22$ & 0.149 \\
\hline Current \& ex-smoker & $89(40.5)$ & $31(36.0)$ & $58(42.6)$ & 0.399 \\
\hline Alcohol drinker & $123(56.2)$ & $48(57.1)$ & $75(55.6)$ & 0.818 \\
\hline Family history of gastric cancer & $95(43.0)$ & $36(42.9)$ & $59(43.1)$ & 0.976 \\
\hline Gastric cancer \& dysplasia & $99(44.8)$ & $30(35.7)$ & $69(50.4)$ & $0.034^{*}$ \\
\hline Gastric dysplasia & $28(28.3)$ & $11(36.7)$ & $17(24.6)$ & \\
\hline $\mathrm{WD}$ or $\mathrm{MD} \mathrm{ADC}$ & $45(45.5)$ & $9(30.0)$ & $36(52.2)$ & \\
\hline PD ADC or SRC & $26(26.2)$ & $10(33.3)$ & $16(23.2)$ & \\
\hline Atrophic gastritis & $129(58.4)$ & $34(40.5)$ & $95(69.3)$ & $<0.001^{*}$ \\
\hline Intestinal metaplasia & $113(50.9)$ & $30(35.7)$ & $83(60.1)$ & $<0.001^{*}$ \\
\hline \multicolumn{5}{|l|}{ Serum pepsinogen } \\
\hline I & $54.14 \pm 40.97$ & $41.85 \pm 28.43$ & $60.66 \pm 44.18$ & $0.001^{*}$ \\
\hline II & $19.25 \pm 16.36$ & $12.67 \pm 12.42$ & $22.90 \pm 16.74$ & $<0.001^{*}$ \\
\hline $\mathrm{I} / \mathrm{II}$ ratio & $3.48 \pm 2.14$ & $4.28 \pm 2.61$ & $2.99 \pm 1.62$ & $<0.001^{*}$ \\
\hline I/II ratio $\leq 3$ & 110 (50.5) & 26 (31.3) & $84(62.2)$ & $<0.001^{*}$ \\
\hline
\end{tabular}

Data are presented as number (\%) or mean \pm SD.

BMI, body mass index; WD, well differentiated; MD, moderately differentiated; ADC, adenocarcinoma; PD, poorly differentiated; SRC, signet ring cell carcinoma.

*Statistically significant, $\mathrm{p}<0.05$. 
TIA; Shima Laboratories, Tokyo, Japan), and the PG I to PG II ratios (PG I / II) were calculated.

\section{Quantitative real-time polymerase chain reaction}

The expression of the ATP $4 A$ mRNA, which is encoded by the gene encoding the $\alpha$-subunit of $\mathrm{H}^{+}, \mathrm{K}^{+}$-ATPase, and $I L-1 B$ mRNA was measured using real-time polymerase chain reaction. Briefly, total RNA were prepared by the extraction from biopsy specimens which obtained in the corpus where the acid secretion is performed by parietal cells avoiding the cancer site with TRIzol reagent (Invitrogen, Carlsbad, CA, USA), and 1,000 ng of RNA were reverse transcribed into complementary DNAs (cDNAs) using the High Capacity cDNA Reverse Transcription kit (Applied Biosystems, Foster City, CA, USA) according to the manufacturers' instructions. Quantitative polymerase chain reaction was performed in 96-well reaction plates using $2 \mu \mathrm{L}$ of complementary DNA in a $20 \mu \mathrm{L}$ reaction mixture containing $2 \times$ SYBR Premix Ex Taq (Takara Bio, Otsu, Japan). Samples were amplified using a StepOne Plus real-time polymerase chain reaction instrument
(Applied Biosystems). The expression levels of mRNA of target gene were compared with the endogenous control $\beta$-actin using the $2^{-\Delta \Delta C T}$ method. ${ }^{20}$ For a longitudinal analysis of changes in expression over time, mRNA expression levels were log-transformed using the equation $\log \left(1+2^{-\Delta \mathrm{CT}}\right){ }^{21}$

\section{Statistical analyses}

The Pearson chi-square test was used for categorical variables and Student t-test for continuous variables. The Mann-Whitney U-test was also used to compare medians when sample size was less than 30. A linear mixed regression analysis using a random intercept model was used to analyze longitudinal data. All analyses were performed using SPSS for Windows version 22.0 (IBM Corp., Armonk, NY, USA).

\section{RESULTS}

\section{Baseline characteristics}

Two hundred twenty-one subjects, including 122 patients
A
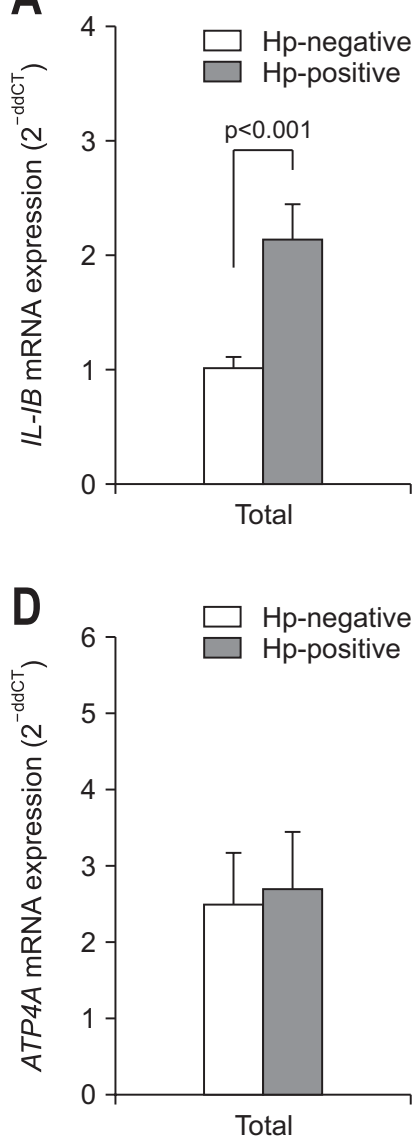

B

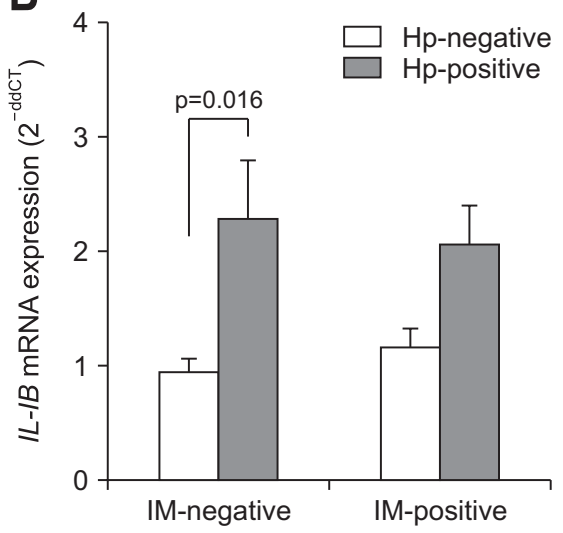

E

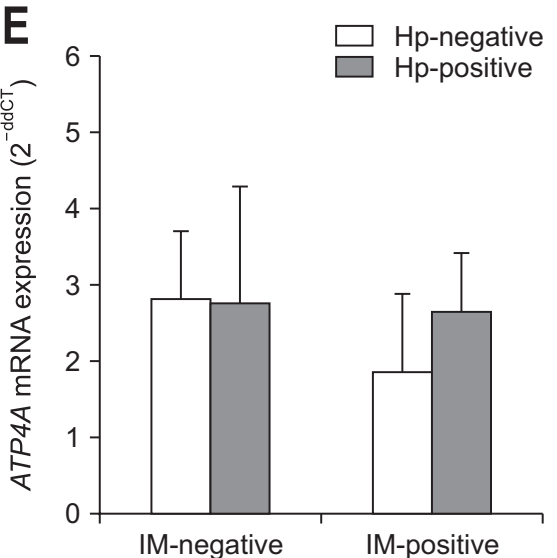



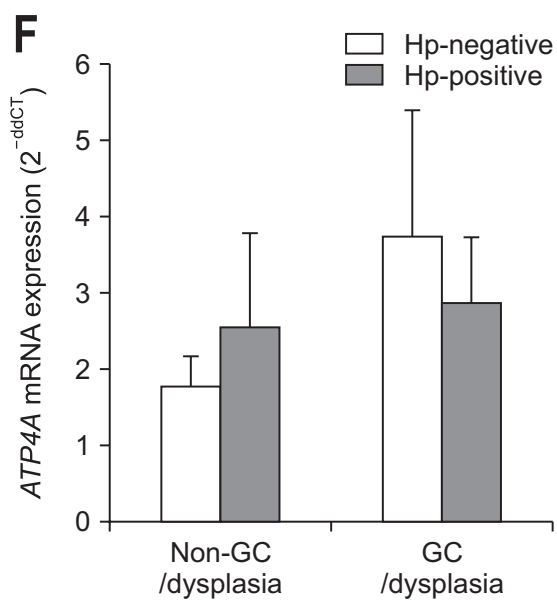

Fig. 2. Comparisons of the mRNA levels of $I L-1 B$ and ATP4A at baseline between the Helicobacter pylori (Hp)-negative and -positive groups. (A) Significantly higher levels of $I L-1 B$ mRNA were detected in the Hp-positive group than in the Hp-negative group (p<0.001). (B) The differences between Hp-negative and -positive groups were significant within the intestinal metaplasia (IM)-negative ( $\mathrm{p}=0.016)$, (C) non-gastric cancer (GC)/ dysplasia $(\mathrm{p}=0.009)$ and $\mathrm{GC} /$ dysplasia subgroups $(\mathrm{p}=0.033)$. (D-F) No significant differences in baseline ATP4A mRNA levels were observed between the Hp-positive and Hp-negative groups. Data are presented as the means \pm standard errors. 
without GC/dysplasia and 99 patients with GC/dysplasia, were enrolled (Fig. 1). One hundred thirty-seven subjects were Hppositive and 84 subjects were Hp-negative. The population included 107 males (48.4\%) and the mean age was 55.2 years (Table 1). Age, body mass index, male sex, ex- or current smok- er, alcohol drinkers, and a family history of GC were not significantly different between the baseline Hp-negative and -positive groups. The proportion of subjects with IM $(60.1 \%$ vs $35.7 \%$, $\mathrm{p}<0.001)$ and mean PG I $(60.66 \pm 44.18$ vs $41.85 \pm 28.43, \mathrm{p}<0.001)$ and PG II levels $(22.90 \pm 16.74$ vs $12.67 \pm 12.42, \mathrm{p}<0.001)$ were
A

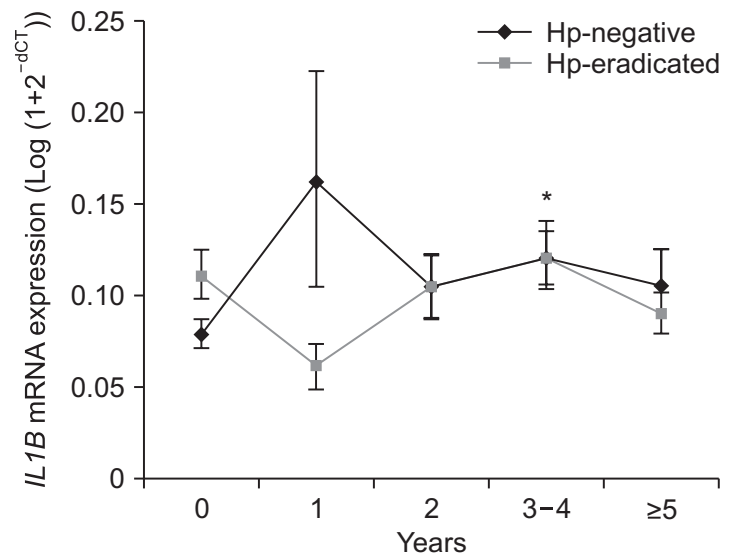

No. of subjects

Hp-negative Hp-eradicated

$\begin{array}{rrrrr}55 & 7 & 26 & 33 & 31 \\ 83 & 20 & 45 & 54 & 70\end{array}$

B

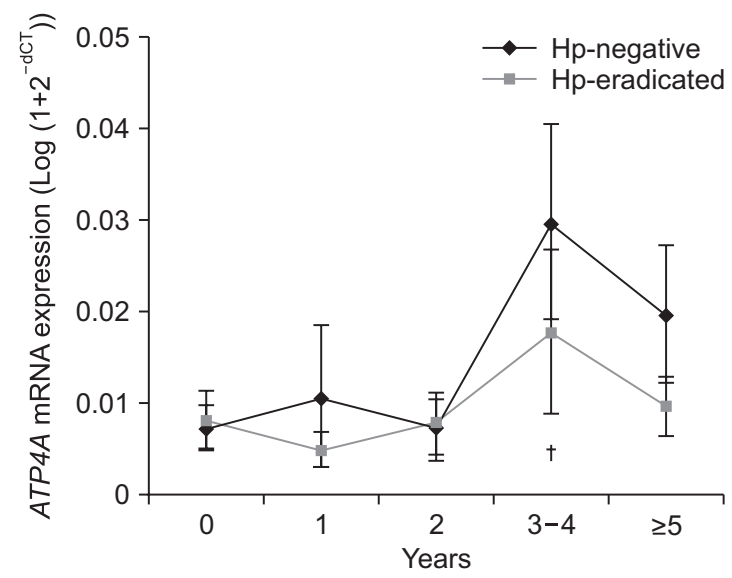

No. of subjects

Hp-negative

Hp-eradicated

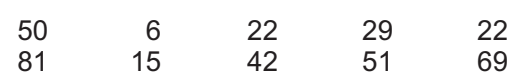

Fig. 3. Changes in the mRNA levels of $I L-1 B$ and ATP $4 A$ over time in the Helicobacter pylori (Hp)-negative and -eradicated groups. (A) The $I L-$ $1 B$ mRNA levels at all time points after Hp eradication were not significantly lower than the values at baseline. The difference in $I L-1 B$ mRNA level between the Hp-negative and -eradicated groups disappeared 1 year after eradication. The level of $I L-1 B$ mRNA at 3-4 years after eradication was significantly higher than the baseline value in the Hp-negative group $(p=0.016)$. (B) No significant changes over time in the ATP4A mRNA level were detected compared to the baseline value in Hp-eradicated group, except at 3-4 years after eradication ( $\mathrm{p}=0.049$ ). Significant differences in the ATP4A mRNA level were not observed between the Hp-negative and -positive groups at any time point. Data are presented as the means \pm standard errors. ${ }^{*} \mathrm{p}$-value $<0.05$ compared to baseline level in Hp-negative subjects; ${ }^{\dagger} \mathrm{p}$-value $<0.05$ compared to baseline level in Hperadicated subjects.

A

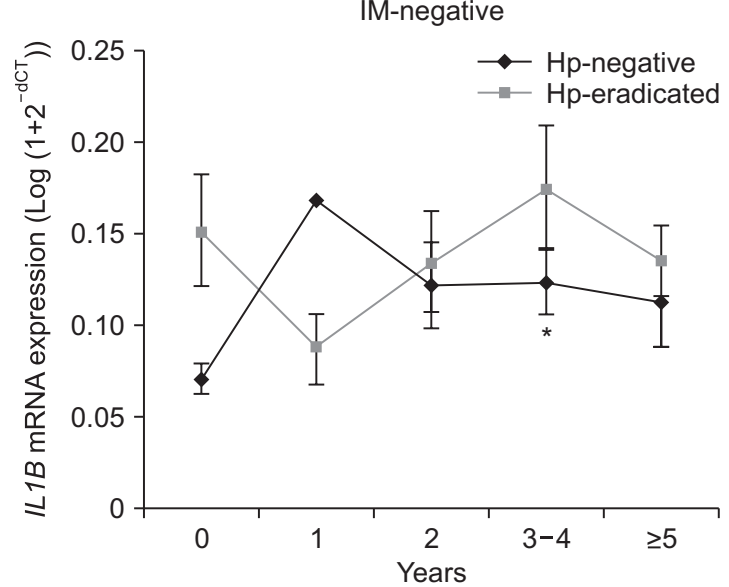

No. of subjects Hp-negative Hp-eradicated

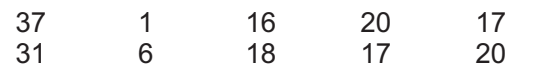

B

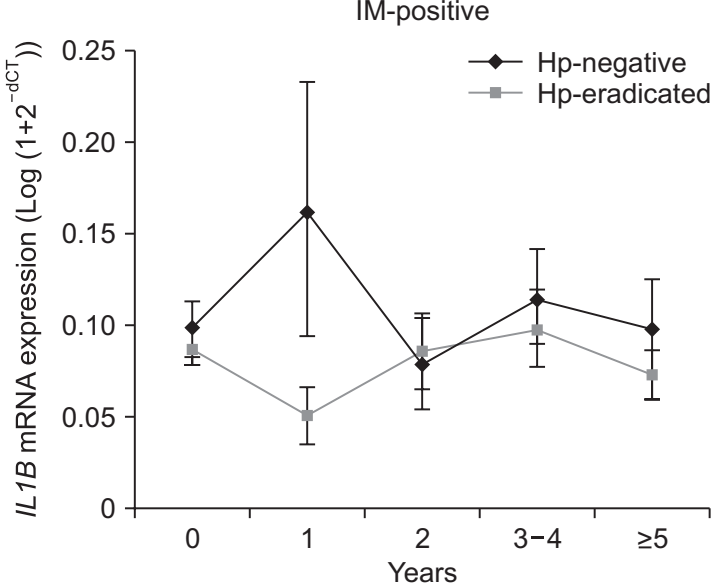

No. of subjects

Hp-negative

Hp-eradicated $\begin{array}{rrrrr}18 & 6 & 10 & 13 & 14 \\ 52 & 14 & 27 & 37 & 50\end{array}$

Fig. 4. Changes in the mRNA levels of $I L-1 B$ over time within the intestinal metaplasia (IM)-negative and -positive subgroups. No significant changes in the mRNA levels of $I L-1 B$ after Helicobacter pylori (Hp) eradication were measured compared with the values measured before Hp eradication at all follow-up time points within the IM-negative (A) and IM-positive (B) subgroups. Within the IM-negative subgroup, the difference in $I L-1 B$ mRNA levels between the Hp-negative and -eradicated groups disappeared 1 year after eradication. The mRNA level of $I L-1 B$ 3-4 years after Hp eradication was significantly higher than the baseline value in the IM-negative and Hp-negative groups ( $\mathrm{p}=0.011)$. Data are presented as the means \pm standard errors. * $p$-value $<0.05$ compared to baseline level in Hp-negative subjects. 
higher and the mean PG I/II ratio $(2.99 \pm 1.62$ vs $4.28 \pm 2.61$, $\mathrm{p}<0.001)$ was lower in the Hp-positive group than in Hpnegative group. The mean follow-up duration was 48.2 months (range, 6 to 136 months).

A

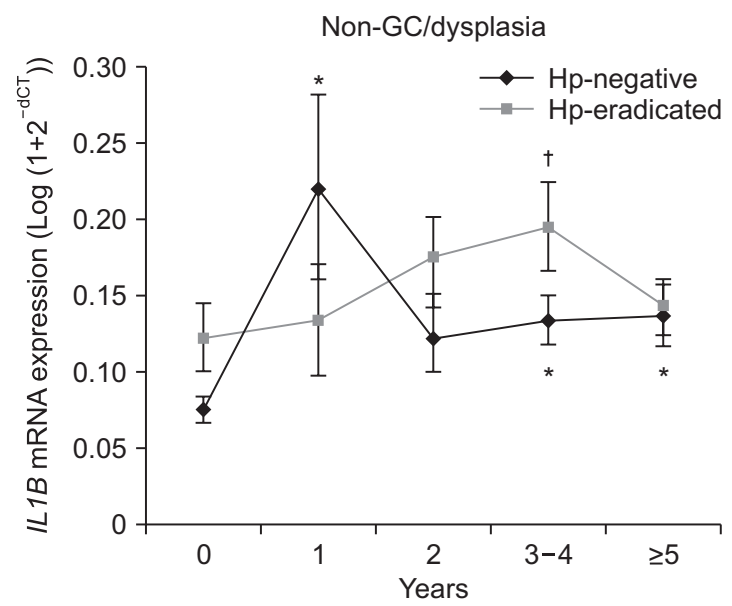

No. of subjects

Hp-negative Hp-eradicated

$\begin{array}{lllll}40 & 2 & 18 & 25 & 22 \\ 43 & 4 & 23 & 27 & 33\end{array}$

\section{IL-1B mRNA expression before and after Hp eradication}

A significantly higher mean baseline level of the $I L-1 B$ mRNA was detected in the Hp-positive group than in the Hp-negative group $(2.15 \pm 3.41$ vs $1.03 \pm 0.86, \mathrm{p}<0.001)$ (Fig. $2 \mathrm{~A})$. In the $a b-$

B

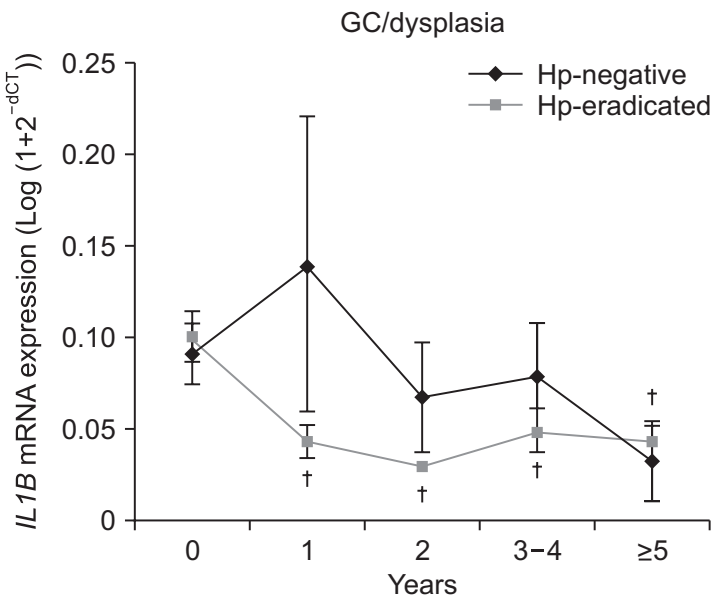

No. of subjects

Hp-negative

Hp-eradicated

Fig. 5. Changes in the mRNA levels of $I L-1 B$ over time within the non-gastric cancer (GC)/dysplasia and GC/dysplasia subgroups. (A) Within the non-GC/dysplasia subgroup, the IL-1B mRNA level 3-4 years after Helicobacter pylori (Hp) eradication was significantly higher than the level before Hp eradication $(\mathrm{p}=0.049)$. Compared to the baseline level, significantly higher mRNA levels of $I L-1 B$ were found 1 year $(p=0.001)$, 3-4 years $(p=0.001)$ and $\geq 5$ years $(p=0.011)$ after eradication in the $\mathrm{GC} /$ dysplasia-negative and Hp-negative subgroups. (B) $I L-1 B$ mRNA was expressed at significantly lower levels at all follow-up time points after Hp eradication compared with the values measured before Hp eradication in the GC/ dysplasia subgroup ( $<<0.05$ for all intervals). The differences in $I L-1 B$ mRNA levels between the Hp-negative and -eradicated groups were not significant within the non-GC/dysplasia and GC/dysplasia subgroups at all time points. Data are presented as the means \pm standard errors. ${ }^{*} \mathrm{p}$-value $<0.05$ compared to baseline level in Hp-negative subjects; ${ }^{\dagger}$-value $<0.05$ compared to baseline level in Hp-eradicated subjects.
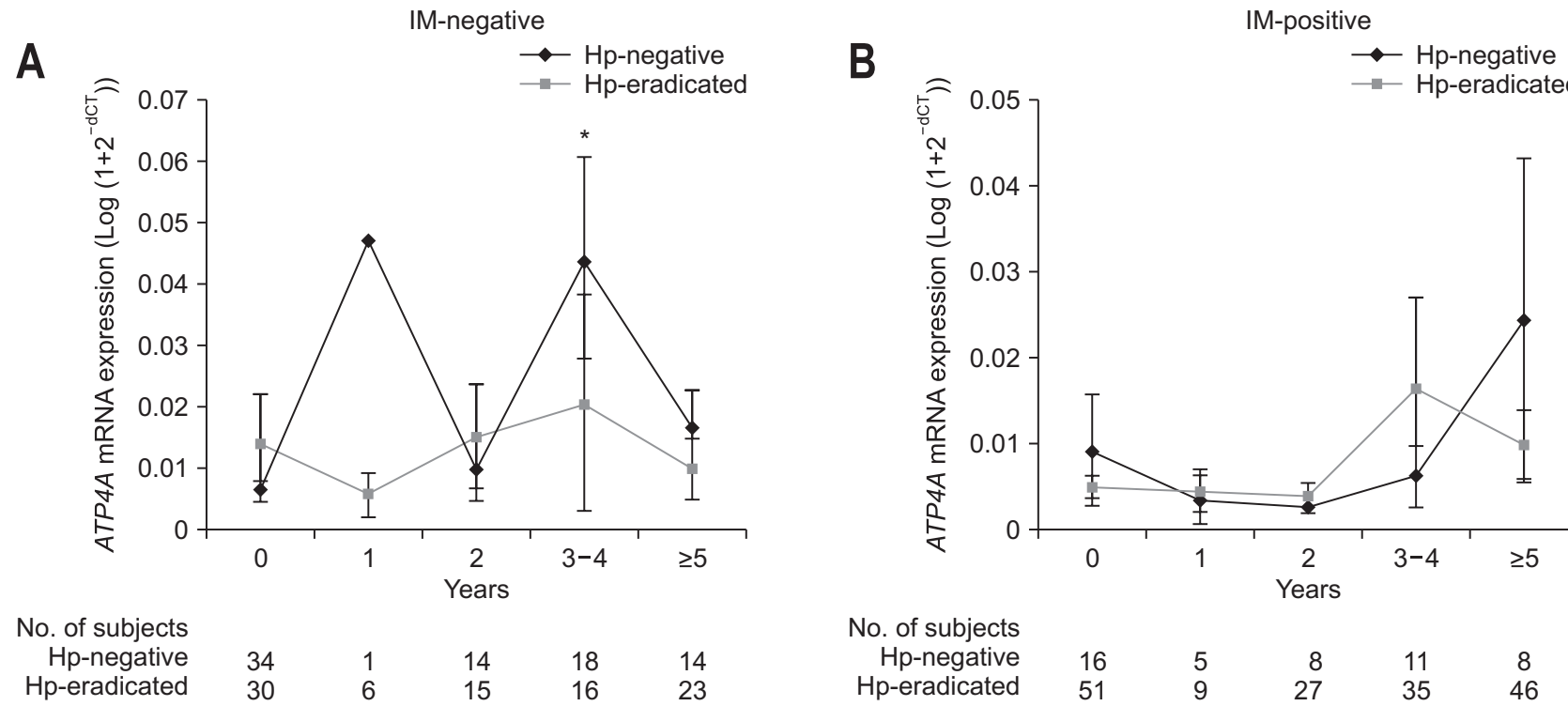

No. of subjects
Hp-negative Hp-eradicated

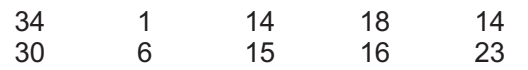

Fig. 6. Changes in the mRNA levels of ATP4A over time within the intestinal metaplasia (IM)-negative and -positive subgroups. No significant changes in the mRNA levels of ATP4A after Helicobacter pylori (Hp) eradication were measured compared with the values measured before Hp eradication at all follow-up time points within the IM-negative (A) and IM-positive (B) subgroups. Within the IM-negative subgroup, the mRNA level of ATP4A 3-4 years after eradication was significantly higher than the baseline level in the Hp-negative group ( $\mathrm{p}=0.033$ ). Data are presented as the means \pm standard errors. ${ }^{*}$ - -value $<0.05$ compared to baseline level in Hp-negative subjects. 
sence of IM, a significant difference in the mean $I L-1 B$ mRNA level was observed between baseline Hp-negative and -positive groups $(0.95 \pm 0.79$ vs $2.28 \pm 3.86, p=0.016)$, while the significant difference disappeared in the presence of IM (Fig. 2B). Within non-GC/dysplasia and GC/dysplasia subgroups, the significant difference between baseline Hp-negative and -positive groups were found (non-GC/dysplasia, $1.01 \pm 0.84$ vs $2.52 \pm 4.52$, $\mathrm{p}=0.009$; GC/dysplasia, $1.06 \pm 0.92$ vs $1.79 \pm 1.74, \mathrm{p}=0.033$ ) (Fig. 2C).

Changes in the levels of the $I L-1 B$ mRNA over time are presented as the mean values of collected data at each interval in Fig. 3. The mean $I L-1 B$ mRNA level at all time points after Hp eradication was not significantly lower than the values at baseline (Fig. 3A). A significant change with time was not observed in Hp-negative group, except at 3 to 4 years ( $p=0.016$ ). The difference in $I L-1 B$ mRNA level between the Hp-eradicated group and Hp-negative group disappeared from 1 year after eradication.

Within IM-negative and -positive subgroup, the mean $I L-1 B$ level after 1, 2, 3-4, and $\geq 5$ years in Hp-eradicated group did not show significant change compared to those at baseline (Fig. 4). The differences in $I L-1 B$ mRNA level between Hp-negative and -eradicated groups disappeared after Hp eradication within IM-negative subgroups.

Within non-GC/dysplasia subgroup, significantly higher levels of the $I L-1 B$ mRNA were detected at 3-4 years after eradication than at the baseline ( $\mathrm{p}=0.049$ ) (Fig. 5A). Within GC/dysplasia subgroup, the mean $I L-1 B$ mRNA levels were significantly lower at all follow-up time points after eradication compared to baseline $I L-1 B$ mRNA levels ( $p<0.05$ for all intervals) (Fig. $5 B)$. The differences in $I L-1 B$ mRNA level between Hp-negative and -eradicated groups were not significant at 1, 2, 3-4, and $\geq 5$ years after $\mathrm{Hp}$ eradication within non-GC/dysplasia and GC/ dysplasia subgroups.

\section{ATP4A mRNA expression before and after Hp eradication}

A significant difference in ATP4A mRNA levels was not observed between Hp-negative and -positive groups at baseline (2.49 \pm 5.95 vs $2.70 \pm 8.67, \mathrm{p}=0.848)$ (Fig. $2 \mathrm{D})$. A statistically significant difference was not observed in subgroups stratified according to the presence of IM (IM-negative, $2.84 \pm 6.24$ vs $2.77 \pm 10.93, p=0.970$; IM-positive, $1.87 \pm 5.43$ vs $2.66 \pm 6.89$, $\mathrm{p}=0.582$ ) (Fig. 2E) and GC/dysplasia (non-GC/dysplasia, $1.77 \pm 3.00$ vs $2.54 \pm 10.04, p=0.599 ; G C /$ dysplasia, $3.75 \pm 6.24$ vs $2.87 \pm 7.16, p=0.608$ ) (Fig. $2 F$ ).

The mean ATP4A mRNA levels measured at only 3 to 4 years after $\mathrm{Hp}$ eradication were significantly higher than the baseline levels ( $p=0.049$ ) (Fig. 3B); however, except that time point, a constant increase with time was not founded in Hp-eradicated group. There were no significant differences in ATP4A mRNA level between Hp-negative and -eradicated groups at any time point.

Within IM-negative and -positive subgroups, constant increases in the level of ATP4A mRNA were not observed after Hp eradication (Fig. 6). In GC/dysplasia subgroup, the mean ATP4A mRNA level was significantly lower than baseline values only

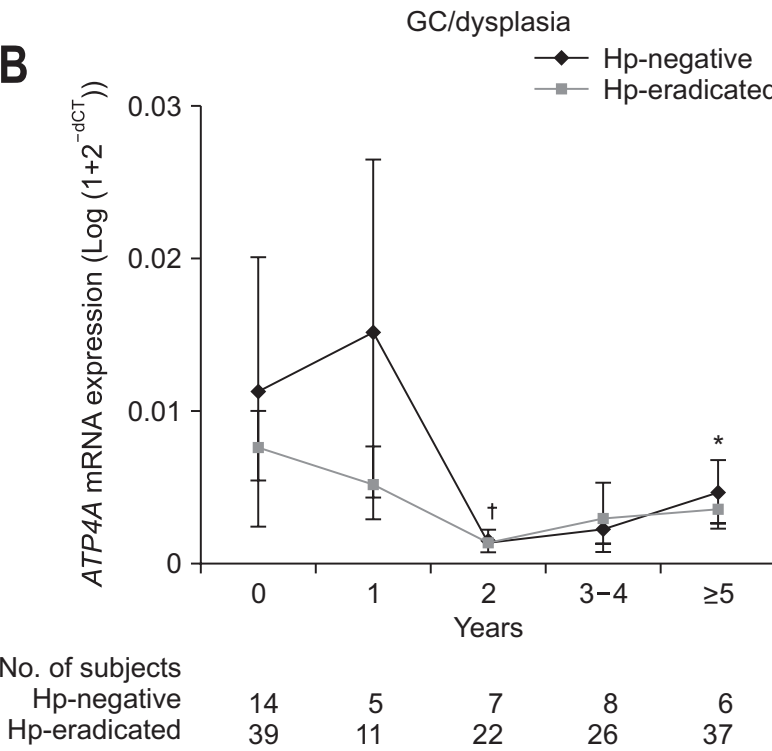

No. of subjects

Hp-negative Hp-eradicated

\section{Non-GC/dysplasia}

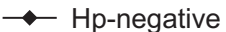

$\rightarrow$ Hp-eradicated

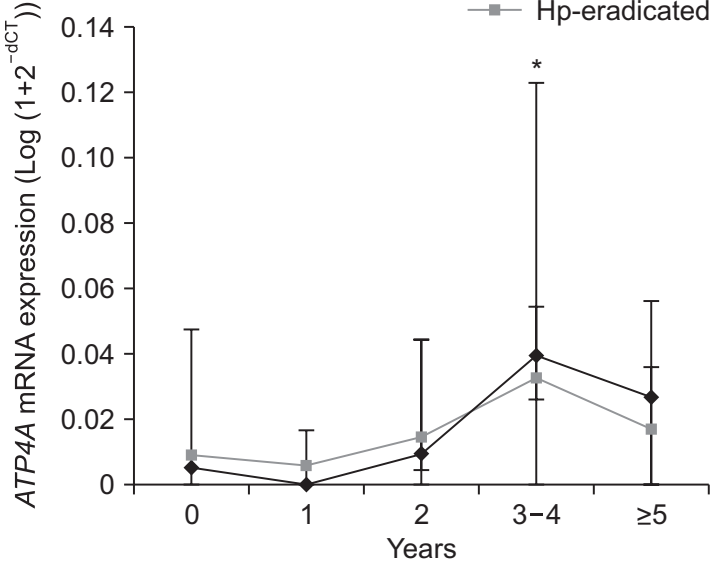

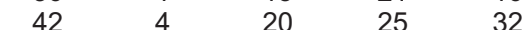

Fig. 7. Changes in the mRNA levels of ATP4A over time within the non-gastric cancer (GC)/dysplasia and GC/dysplasia subgroups. The mRNA level of ATP4A 2 years after Helicobacter pylori (Hp) eradication was significantly lower than the baseline level within the GC/dysplasia subgroup ( $\mathrm{p}=0.012)$; at all other time points, no significant changes in the ATP4A mRNA level were detected after Hp eradication in the subgroups stratified by the presence of GC/dysplasia. In the Hp-negative group, significant differences in the ATP4A mRNA level were found 3-4 years after eradication in the non-GC/dysplasia subgroup $(\mathrm{p}=0.027)$ and $\geq 5$ years in the $\mathrm{GC} /$ dysplasia subgroup $(\mathrm{p}=0.007)$ compared to the baseline values. Data are presented as the means \pm standard errors. ${ }^{*}$ p-value $<0.05$ compared to baseline level in Hp-negative subjects; ${ }^{\dagger}$ p-value $<0.05$ compared to baseline level in Hp-eradicated subjects. 
at 2 years after Hp eradication ( $\mathrm{p}=0.012$ ) (Fig. 7). The difference in $I L-1 B$ mRNA level between the Hp-eradicated and -negative group were not significant at baseline and after 1, 2, 3-4, and $\geq 5$ years in subgroups stratified to presence of IM or GC/dysplasia.

\section{Serum PG levels before and after Hp eradication}

At baseline, mean PG I and PG II levels were higher and the mean PG I/II ratio was lower in the Hp-positive group than in Hp-negative group (Table 1). After Hp eradication, PG I levels measured at 1 year were significantly lower than the baseline levels $(\mathrm{p}=0.012)$. With the exception of that time point, no significant changes were observed (Fig. 8A). PG II levels decreased and the PG I/II ratio increased significantly at all time points after eradication compared to baseline levels (Fig. 8B and C).

\section{DISCUSSION}

Based on our results, a significantly higher level of the $I L$ $1 B$ mRNA was detected in the Hp-positive group than in the

A
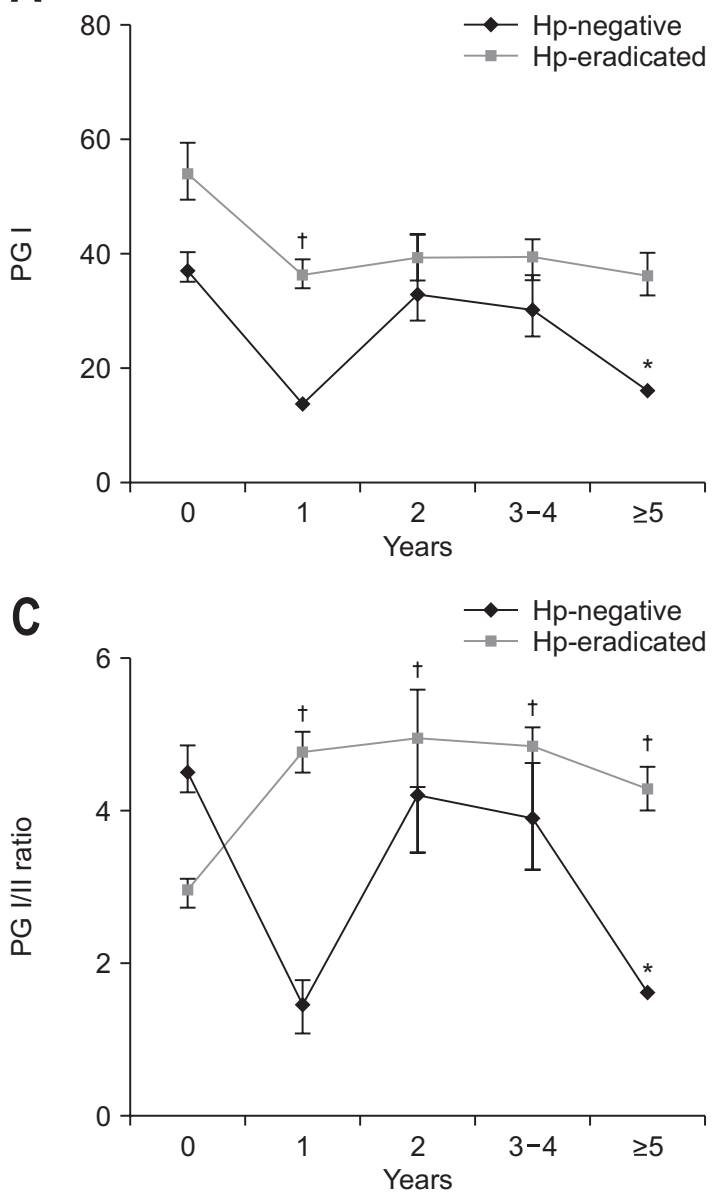

Hp-negative group. The difference in the $I L-1 B$ mRNA level between Hp-negative and-positive disappeared at 1, 2, 3-4, and $\geq 5$ years after $H p$ eradication. The $I L-1 B$ mRNA levels measured at all follow-up time points were significantly lower than the values measured before Hp eradication in patients with GC/ dysplasia. No studies have reported the long-term effects of the eradication of $\mathrm{Hp}$ on gastric mucosal $\mathrm{IL}-1 \beta$ levels. In contrast, significant differences in the ATP4A mRNA level at baseline were not observed between Hp-negative and -positive groups, and no significant changes in the ATP4A mRNA level were detected after Hp eradication.

$\mathrm{IL}-1 \beta$, a pro-inflammatory cytokine, is expressed at high levels in the Hp-infected gastric mucosa and is a potent inhibitor of gastric acid secretion. In addition, IL-1 $\beta$ plays important roles in carcinogenesis as a factor that defines the tumor microenvironment through the activation of nuclear factor- $\mathrm{kB}$ and modulation of the Wnt pathway. ${ }^{22}$ Therefore, the significant decrease in $I L-1 B$ mRNA levels observed after Hp eradication in patients with GC/dysplasia implies an important effect of Hp eradication
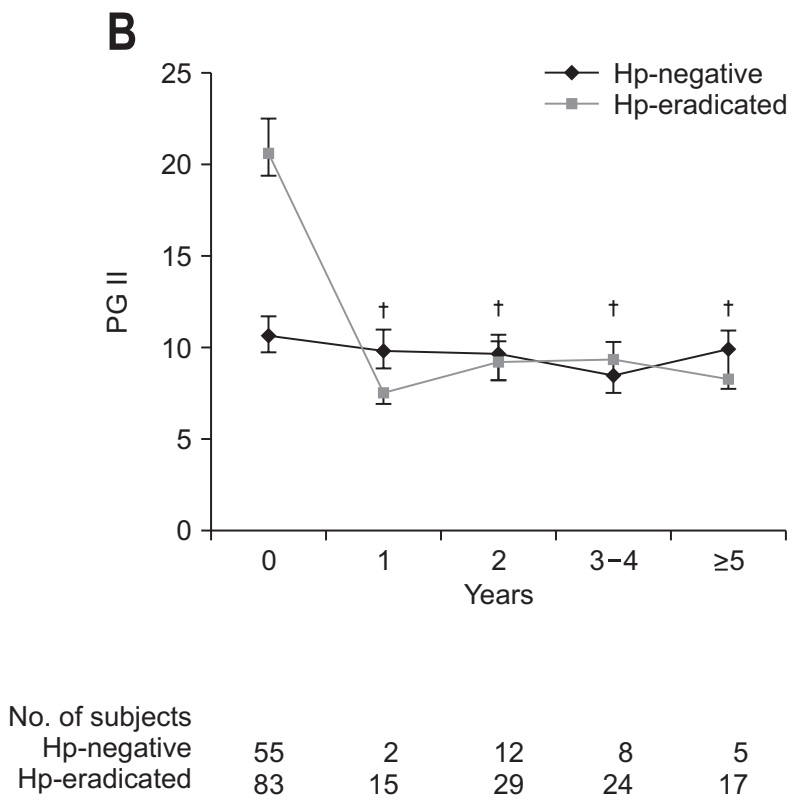

Fig. 8. Changes in serum pepsinogen (PG) I (A) and II (B) levels and the PG I/II ratio (C) over time. Significantly lower PG II levels and higher PG I/II ratios were observed at all follow-up time points after Helicobacter pylori (Hp) eradication compared with the values measured before Hp eradication. Data are presented as the means \pm standard errors. ${ }^{*}$-value $<0.05$ compared to baseline level in Hp-negative subjects; ${ }^{\dagger} p$-value $<0.05$ compared to baseline level in Hp-eradicated subjects. 
on improving the tumor microenvironment and subsequently preventing carcinogenesis, and not only restoring gastric acid secretion. As shown in previous studies from our research group, Hp infection triggers the transforming growth factor- $\beta 1$ induced epithelial-mesenchymal transition and the emergence of GC stem cells. Hp eradication is an effective method for preventing the development of primary GC by inhibiting these pathway. ${ }^{23,24}$ Together with our previous studies, the present study supports the hypothesis that Hp eradication decreases the expression of factors causing GC development.

Hp or its products inhibit the activity of the promoter of the alpha-subunit of $\mathrm{H}^{+}, \mathrm{K}^{+}$-ATPase and suppress the expression of the $\mathrm{H}^{+}, \mathrm{K}^{+}$-ATPase. ${ }^{3,25}$ The direct inhibition of $\mathrm{H}^{+}, \mathrm{K}^{+}$-ATPase, upregulation of IL-1 $\beta$ and tumor necrosis factor- $\alpha$, and loss of parietal cells by chronic inflammation result in a low level of acid secretion in patients with chronic corpus-predominant gastritis. ${ }^{26}$ A few studies have examined the changes in acid secretion after Hp eradication, particularly the relationship with the reversibility of atrophic gastritis in the corpus, ${ }^{8,10}$ but long-term follow-up results for gastric $\mathrm{H}^{+}, \mathrm{K}^{+}$-ATPase activities are scarce. The strength of the present study is that we directly measured the levels of the ATP $4 A$ mRNA and evaluated the changes over 5 years in both Hp-negative and -eradicated subjects. However, our data did not show significant increases in ATP4A mRNA levels after Hp eradication, although $I L-1 B$ mRNA levels decreased and the PG I/II ratio increased after Hp eradication in patients with GC/dysplasia. We are unable to clearly explain the lack of significance differences in changes in the levels of the ATP4A mRNA in the Hp-eradicated group. $\mathrm{H}^{+}, \mathrm{K}^{+}$-ATPase, as a proton pump, is the common pathway mediating the secretion of gastric acid and is known to be a marker of parietal cell function. ${ }^{27}$ We measured the levels of the ATP $4 A$ mRNA from a few specimens of gastric corpus mucosa, and the function of parietal cells in our samples might not have completely recovered or might not be reversible, at least in some patients. The complete recovery of the function of gastric $\mathrm{H}^{+}, \mathrm{K}^{+}$-ATPase might require additional time after the reduction in IL- $1 \beta$ levels and improvement in atrophy, and some of the recovered gastric $\mathrm{H}^{+}, \mathrm{K}^{+}$ATPase might display hyperactivity to decrease the gastric $\mathrm{pH}$. In the present study, the levels of the ATP4A mRNA in individual patients at follow-up varied substantially, from decrease of less than 0.01-fold to an increase of 290-fold compared to the value measured in each individual before eradication. Therefore, the wide range of ATP4A mRNA levels in individuals might be responsible for the lack of a statistically significant difference. In addition, the ATP4A mRNA was measured several times in the present study to increase the reproducibility and to overcome the wide variation.

Because our result did not reveal a significant increase in the expression of the ATP4A mRNA over time in subjects with Hp eradication, we evaluated serum PG levels, which are regarded as a reliable gastric secretory parameter. PG I and particularly
PG II levels increase with an increasing severity of Hp-related gastritis, ${ }^{28}$ however, when atrophy occurs in the corpus, the level of PG I decreases. PG II is secreted at high levels. Therefore, the level of PG II remains high or stable, and the PG I/II ratio decreases. Several studies have reported a decrease in PG I levels and more remarkably PG II levels, and an increase in the PG I/II ratio after the eradication of Hp after short-term follow-up. ${ }^{12,29-34}$ In the present study, PG II levels decreased and the PG I/II ratio increased significantly after Hp eradication. To the best of our knowledge, the follow-up period of our study is much longer than in previous researches.

A limitation of our study was the rather small sample size. Our previous study reporting the reversibility of IM in $442 \mathrm{Hp}-$ eradicated subjects included a sufficient number of subjects to show statistically significant differences, considering the gradual and slow regression of IM compared to atrophic gastritis. ${ }^{17}$ The small number of subjects included in the present study might explain the lack of a significant change in ATP4A mRNA levels, particularly in the subgroup analysis stratified according to IM status. In addition, the difficulty in obtaining the measurement might have resulted in the lack of statistical significance. Another limitation is that we did not measure the change in the gastric juice $\mathrm{pH}$ which is a more exact parameter to evaluate the recovery of gastric acid secretion. Our research group previously measured the gastric juice $\mathrm{pH}$ and reported a significant relationship between chronic $\mathrm{Hp}$ infection and gastric juice $\mathrm{pH}$ $\geq 3 .^{35}$ We tried to follow up with the patients enrolled in that study, but the aspiration of the gastric juice was very difficult and time-consuming, and a number of patients whose gastric juice was obtained in the previous study could not be followed. Instead, we measured mucosal levels of the $I L-1 B$ and $A T P 4 A$ mRNAs to confirm the recovery of gastric acid secretion. Furuta et al. ${ }^{9}$ previously reported that the amount of $\mathrm{H}^{+}, \mathrm{K}^{+}$-ATPase mRNA in the gastric fundus was increased in Hp-eradicated patients, in whom significant decreases in $\mathrm{pH}$ of gastric juice and serum gastrin levels were observed. These data supported a relationship between the increased $\mathrm{H}^{+}, \mathrm{K}^{+}$-ATPase expression and recovery of gastric acid secretion.

In conclusion, our long-term follow-up study revealed that $I L-1 B$ mRNA level in Hp-positive groups was significantly higher than in Hp-negative group, and the difference in the $I L$ $1 B$ mRNA level between Hp-negative and -positive disappeared after Hp eradication in IM-negative subgroup. The expression of the $I L-1 B$ mRNA after Hp eradication decreased constantly compared to the expression levels measured before Hp eradication in GC/dysplasia subgroup. The infection of Hp has an effect on the level of $I L-1 B$ mRNA in only IM-negative subjects and the effect of $\mathrm{Hp}$ eradication on the constant reduction in the levels of the $I L-1 B$ mRNA in patients with early GC/dysplasia supports the hypothesis that Hp eradication helps to further suppress gastric carcinogenesis. 


\section{CONFLICTS OF INTEREST}

No potential conflict of interest relevant to this article was reported.

\section{ACKNOWLEDGEMENTS}

This work was supported by a grant (2011-0030001) of the National Research Foundation (NRF) for the Global Core Research Center (GCRC) funded by The Ministry of Science, ICT and Future Planning (MSIP), Republic of Korea.

\section{AUTHOR CONTRIBUTIONS}

Conceptualization: N.K. Data curation: N.K. Formal analysis: H.J.K., J.H.P. Funding acquisition: N.K. Methodology: N.K., J.H.P. Project administration: N.K. Visualization: H.J.K., S.C. Writingoriginal draft: H.J.K. Writing - review \& editing: C.M.S., O.J.L. Approval of final manuscript: all authors.

\section{ORCID}

Hee Jin Kim

Nayoung Kim

Ji Hyun Park

Sunkyu Choi

Cheol Min Shin

Ok Jae Lee https://orcid.org/0000-0001-9608-0348 https://orcid.org/0000-0002-9397-0406 https://orcid.org/0000-0002-4809-8700 https://orcid.org/0000-0001-8827-7060 https://orcid.org/0000-0003-2265-9845 https://orcid.org/0000-0002-4016-4443

\section{REFERENCES}

1. Smolka AJ, Backert S. How Helicobacter pylori infection controls gastric acid secretion. J Gastroenterol 2012;47:609-618.

2. Shin JM, Kim N. Pharmacokinetics and pharmacodynamics of the proton pump inhibitors. J Neurogastroenterol Motil 2013;19:2535.

3. Göõz M, Hammond CE, Larsen K, Mukhin YV, Smolka AJ. Inhibition of human gastric $\mathrm{H}(+)-\mathrm{K}(+)-A T P a s e$ alpha-subunit gene expression by Helicobacter pylori. Am J Physiol Gastrointest Liver Physiol 2000;278:G981-G991.

4. Beales IL, Calam J. Interleukin 1 beta and tumour necrosis factor alpha inhibit acid secretion in cultured rabbit parietal cells by multiple pathways. Gut 1998;42:227-234.

5. Amedei A, Munari F, Bella CD, et al. Helicobacter pylori secreted peptidyl prolyl cis, trans-isomerase drives Th17 inflammation in gastric adenocarcinoma. Intern Emerg Med 2014;9:303-309.

6. Correa P. Human gastric carcinogenesis: a multistep and multifactorial process: first American Cancer Society Award Lecture on Cancer Epidemiology and Prevention. Cancer Res 1992;52:67356740 .

7. Kuipers EJ, Uyterlinde AM, Peña AS, et al. Long-term sequelae of Helicobacter pylori gastritis. Lancet 1995;345:1525-1528.
8. Osawa $\mathrm{H}$, Kita H, Ohnishi $\mathrm{H}$, et al. Helicobacter pylori eradication induces marked increase in $\mathrm{H}+/ \mathrm{K}+-$ adenosine triphosphatase expression without altering parietal cell number in human gastric mucosa. Gut 2006;55:152-157.

9. Furuta T, Baba S, Takashima $\mathrm{M}$, et al. $\mathrm{H}+/ \mathrm{K}+-$-adenosine triphosphatase mRNA in gastric fundic gland mucosa in patients infected with Helicobacter pylori. Scand J Gastroenterol 1999;34:384-390.

10. Iijima K, Sekine H, Koike T, Imatani A, Ohara S, Shimosegawa T. Long-term effect of Helicobacter pylori eradication on the reversibility of acid secretion in profound hypochlorhydria. Aliment Pharmacol Ther 2004;19:1181-1188.

11. Kato S, Matsukura N, Matsuda N, Tsuchiya S, Naito Z, Tajiri T. Normalization of $\mathrm{pH}$ level and gastric mucosa after eradication of H. pylori in the remnant stomach. J Gastroenterol Hepatol 2008;23 Suppl 2:S258-S261.

12. Iijima K, Koike T, Abe $\mathrm{Y}$, et al. Alteration of correlation between serum pepsinogen concentrations and gastric acid secretion after $\mathrm{H}$. pylori eradication. J Gastroenterol 2009;44:819-825.

13. Beales IL, Calam J. Inhibition of carbachol stimulated acid secretion by interleukin 1 beta in rabbit parietal cells requires protein kinase C. Gut 2001;48:782-789.

14. Takashima M, Furuta T, Hanai H, Sugimura H, Kaneko E. Effects of Helicobacter pylori infection on gastric acid secretion and serum gastrin levels in Mongolian gerbils. Gut 2001;48:765-773.

15. Wang M, Furuta T, Takashima M, et al. Relation between interleukin-1beta messenger RNA in gastric fundic mucosa and gastric juice $\mathrm{pH}$ in patients infected with Helicobacter pylori. J Gastroenterol 1999;34 Suppl 11:10-17.

16. Chang YW, Oh HC, Jang JY, et al. IL-1beta and IL-8, matrix metalloproteinase 3, and pepsinogen secretion before and after $\mathrm{H}$. pylori eradication in gastroduodenal phenotypes. Scand J Gastroenterol 2008;43:1184-1193.

17. Hwang YJ, Kim N, Lee HS, et al. Reversibility of atrophic gastritis and intestinal metaplasia after Helicobacter pylori eradication: a prospective study for up to 10 years. Aliment Pharmacol Ther 2018;47:380-390.

18. Bair MJ, Wu MS, Chang WH, et al. Spontaneous clearance of Helicobacter pylori colonization in patients with partial gastrectomy: correlates with operative procedures and duration after operation. J Formos Med Assoc 2009;108:13-19.

19. World Medical Association. World Medical Association Declaration of Helsinki: ethical principles for medical research involving human subjects. Nurs Ethics 2002;9:105-109.

20. Schmittgen TD, Livak KJ. Analyzing real-time PCR data by the comparative C(T) method. Nat Protoc 2008;3:1101-1108.

21. Shin CM, Kim N, Chang H, Kim JS, Lee DH, Jung HC. Follow-up study on CDX1 and CDX2 mRNA expression in noncancerous gastric mucosae after Helicobacter pylori eradication. Dig Dis Sci 2016;61:1051-1059.

22. Quante M, Varga J, Wang TC, Greten FR. The gastrointestinal tumor microenvironment. Gastroenterology 2013;145:63-78.

23. Kim N. Chemoprevention of gastric cancer by Helicobacter pylori 
eradication and its underlying mechanism. J Gastroenterol Hepatol 2019;34:1287-1295.

24. Choi YJ, Kim N, Chang H, et al. Helicobacter pylori-induced epithelial-mesenchymal transition, a potential role of gastric cancer initiation and an emergence of stem cells. Carcinogenesis 2015;36:553-563.

25. Yao X, Smolka AJ. Gastric parietal cell physiology and Helicobacter pylori-induced disease. Gastroenterology 2019;156:21582173.

26. Kim N, Choi YJ. Change of acid secretion, ghrelin and leptin by H. pylori. In: Kim N, ed. Helicobacter pylori. Singapore: Springer Singapore, 2016:53-76.

27. Du GM, Shi ZM, Wei XH, Liu MJ, Zhang L, Zhao RQ. Expression of gastric ghrelin and $\mathrm{H}(+)-\mathrm{K}(+)-A T P a s e ~ m R N A$ in weanling piglets and effect of ghrelin on $\mathrm{H}(+)-\mathrm{K}(+)-A T P a s e$ expression and activity in gastric mucosal cells in vitro. Res Vet Sci 2007;82:99104.

28. Lorente S, Doiz O, Trinidad Serrano M, Castillo J, Lanas A. Helicobacter pylori stimulates pepsinogen secretion from isolated human peptic cells. Gut 2002;50:13-18.

29. Kawai T, Miki K, Ichinose M, et al. Changes in evaluation of the pepsinogen test result following Helicobacter pylori eradication therapy in Japan. Inflammopharmacology 2007;15:31-35.
30. Ohkusa T, Miwa H, Nomura T, et al. Improvement in serum pepsinogens and gastrin in long-term monitoring after eradication of Helicobacter pylori: comparison with $\mathrm{H}$. pylori-negative patients. Aliment Pharmacol Ther 2004;20 Suppl 1:25-32.

31. Pimanov SI, Makarenko EV, Voropaeva AV, Matveenko ME, Voropaev EV. Helicobacter pylori eradication improves gastric histology and decreases serum gastrin, pepsinogen I and pepsinogen II levels in patients with duodenal ulcer. J Gastroenterol Hepatol 2008;23:1666-1671.

32. Daugule I, Ruskule A, Moisejevs G, et al. Long-term dynamics of gastric biomarkers after eradication of Helicobacter pylori infection. Eur J Gastroenterol Hepatol 2015;27:501-505.

33. Nam SY, Jeon SW, Lee HS, Kwon YH, Park H, Choi JW. Longterm follow-up of pepsinogen I/II ratio after eradication of Helicobacter pylori in patients who underwent endoscopic mucosal resection for gastric cancer. Dig Liver Dis 2017;49:500-506.

34. Baek SM, Kim N, Kwon YJ, et al. Role of serum pepsinogen II and Helicobacter pylori status in the detection of diffuse-type early gastric cancer in young individuals in South Korea. Gut Liver 2020;14:439-449.

35. Sung J, Kim N, Lee J, et al. Associations among gastric juice $\mathrm{pH}$, atrophic gastritis, intestinal metaplasia and Helicobacter pylori infection. Gut Liver 2018;12:158-164. 